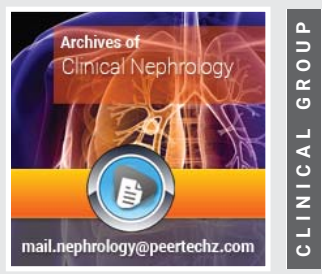

\title{
Heat-Shock Protein 27 kinetics in end stage renal disease patients
}

Received: 12 October, 2015

Accepted: 14 September, 2020

Published: 16 September, 2020

*Corresponding author: I Griveas, Nephrology Department, 417 Army Share Fund Hospital (NIMTS), Athens, Greece, E-mail: giannisgriv@hotmail.com

https://www.peertechz.com

Check for updates

\section{Griveas*}

Nephrology Department, 417 Army Share Fund Hospital (NIMTS), Athens, Greece

\section{Introduction}

Atherosclerosis is one of the most significant yet unresolved problems in patients on regular Hemodialysis (HD) with major impact on morbidity and mortality of patients with end-stage renal disease (ESRD). There is growing evidence that atherosclerosis may-at least in part- result from autoimmune processes, in which the family of HeatShock Proteins (HSP) may be involved [1]. HSP are a class of functionally related proteins that are synthesized byorganisms or cells and complicated in the folding and unfolding of other proteins, while their expression is increased when cells are exposed to heat or other stressogenic physiological, physical, or chemical stimuli (i.e. oxidative stress, cytokines and growth factors). When stress-exposed, the cells respond by drastic modifications of the different cytoskeletal networks and by selective increase in HSP synthesis.

Experimental evidence has shown that expression of HSP on endothelial cells triggers early inflammatory atherosclerotic changes [2]. Besides their well-established roles in cell survival (necrosis and apoptosis), there is growing evidence regarding chaperone functions in physiological adaptation during cardiac hypertrophy, vessel wall injury, oxidative stress and aging [3]. Howeverdata are missingregarding connection between endothelial dysfunction, HSP and ESRD which is characterized by inflammation, mitochondrial dysfunction, oxidative stress and augmented apoptosis, abnormalities that are more evident during dialysis, while in end-stage renal disease activated peripheral mononuclear cells generate inflammatory cytokines [4].

Aim of our study was to estimate kinetics of HSP and cytokines during a HD session comparing also new HD modalities, dialyzers, and the differences between dialyzed patients during a specific period.

\section{Materials-methods}

A group of 20 patients undergoing HD were recruited,in order to materialize the above hypothesis. Only subjects on maintenance HD for more than 90 days included. Blood samples were collected before HD session and after the end of HD and dialysate samples were collected before the end of HD session.

The blood and dialysate samples were used in order to determine: IL-1 $\alpha$, IL-1 $\beta$, IL-2, IL-5, IL-6, IL-8, IL-10, TNF- $\alpha$, HSP-27, caspase 3. For our measurements we used Luminex technology. It is a proven multiplex platform that uses precise ratios of two fluorophores to create 100 different microsphereor bead sets. Each set is distinguished based on its internal dye ratios and can therefore carry a unique biological reagent. Antibodies, proteins or nucleid acids are bound to the bead surface and serve as targets or as capture reagents for targets (Figure 1). With the above measurements we tried to evaluate kinetics of cytokines and HSP and simultaneously their clearances, during a session of HD.

Blood samples before HD session were used for determination also of $\mathrm{Hb}$, Hct, ferritin, PTH, CRP, albumin. With all the above values we will have the chance to verify any kind of connection between cytokines, HSP and signs of chronic inflammation, anemia, secondary hyperparathyroidism, malnutrition, which are basic elements of endothelial dysfunction.

Our research plan also includes comparison between different modalities of HD (regular HD vs on-line HD), different dialyzers (biocompatibility test) using as basic tools HSP and cytokines. The same group of patients has been tested using the same parameters, after 3 months period, in order to compare any possible changes in some of the patients' characteristics (e.g. hematocrit) on the basis of cytokine and HSP levels. 


\section{Results}

Biochemical profile of the participants is described in Table 1. ESRD patients were adequately dialysed, as evidenced by a urea reduction ratio of $70.2 \pm 4 \%$. Mean blood flow rate was $335 \pm 12.3 \mathrm{ml} / \mathrm{min}$ and dialysate flow rate was $700 \mathrm{ml} / \mathrm{min}$ in all patients. Net ultrafiltration was $1.2 \pm 0.92 \mathrm{~L}$. Endotoxin level was below $0.1 \mathrm{EU} / \mathrm{ml}$ and bacterial culture was negative in all dialysate samples.

HSP-27 expression was significantly higher $(\mathrm{p}<0.05)$ at the end of HD session than before HD session (Figure 2). Evaluating all the other parameters, we did not observe any significant differences during HD session (Figure 3). Despite of that notice the general idea is that all cytokines tend to get lower at the end of session with exception of IL- 6 which gets higher.

We compared patients undergoing HD with low and high flux membranes on the basis of the above parameters (Table 2). We did not recognize any significant differences among patients receiving HD either with low flux or with high flux dialyzers. On the other hand some key points seem to be very interesting. At first, values of HSP-27 were generally higher in patients with low flux membranes than in those with high flux. In dialysate, HSP-27 was slightly detectable. All the other cytokines do not seem to have a specific pattern of behavior under the influence of type of membrane. The only common point is that all cytokines were not detectable at all in dialysate.

We also compared patients undergoing HD with synthetic membranes or natural polymers on the basis of the above parameters (Table 3). HSP-27 were significantly higher in patients undergoing $\mathrm{HD}$ with natural polymers. On the contrary, values of cytokines were generally higher in patients receiving $\mathrm{HD}$ with synthetic membranes with the exeption of IL-10. In IL-1A pre-HD and in IL-1 $\beta, T N F-\alpha$ at the end of HD these differences were significant.

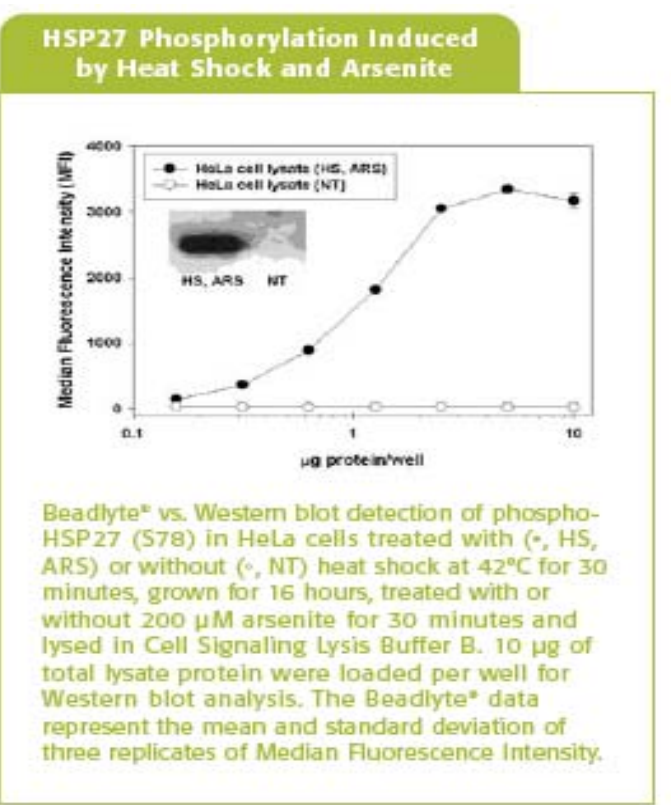

Figure 1: Application of Luminex technology for determination of HSP 27.
Table 1: Biochemical profile of participants.

\begin{tabular}{|c|c|}
\hline Hb & $12.72+/-1.09$ \\
\hline Hct & $37.84+/-3.72$ \\
\hline PTH & $306.16+/-289.45$ \\
\hline Albumine & $4.33+/-0.36$ \\
\hline CRP & $1.36+/-1.76$ \\
\hline Ferritine & $385.41+/-290.52$ \\
\hline HSP 27 Pre-HD & $823.42+/-528.40$ \\
\hline HSP 27 End-HD & $1210.92+/-824.10$ \\
\hline HSP 27 dialysate & $3.32+/-5.86$ \\
\hline CASPASE Pre-HD & $28.15+/-50.41$ \\
\hline CASPASE End-HD & $28.46+/-41.42$ \\
\hline CASPASE dialysate & 0 \\
\hline IL-1A Pre-HD & $40.74+/-39.40$ \\
\hline IL-1A End-HD & $35.98+/-33.55$ \\
\hline IL-1A dialysate & $6+/-0.93$ \\
\hline IL-1B Pre-HD & $7.19+/-20.35$ \\
\hline IL-1B End-HD & $2.42+/-3.63$ \\
\hline IL-1B dialysate & 0 \\
\hline IL-2 End-HD & $5.55+/-4.59$ \\
\hline IL-2 dialysate & 0 \\
\hline IL-5 Pre-HD & 0 \\
\hline IL-5 End-HD & 0 \\
\hline IL-5 dialysate & $09.20+/-97.32$ \\
\hline IL-6 Pre-HD & $75.46+/-103.74$ \\
\hline IL-6 End-HD & 0 \\
\hline IL-6 dialysate & $33.19+/-26.33$ \\
\hline IL-8 Pre-HD & $31.70+/-23.92$ \\
\hline IL-8 End-HD & 0 \\
\hline IL-8 dialysate & $35.37+/-13.52$ \\
\hline IL-10 Pre-HD & 0 \\
\hline IL-10 End-HD & 0 \\
\hline IL-10 dialysate & \\
\hline
\end{tabular}

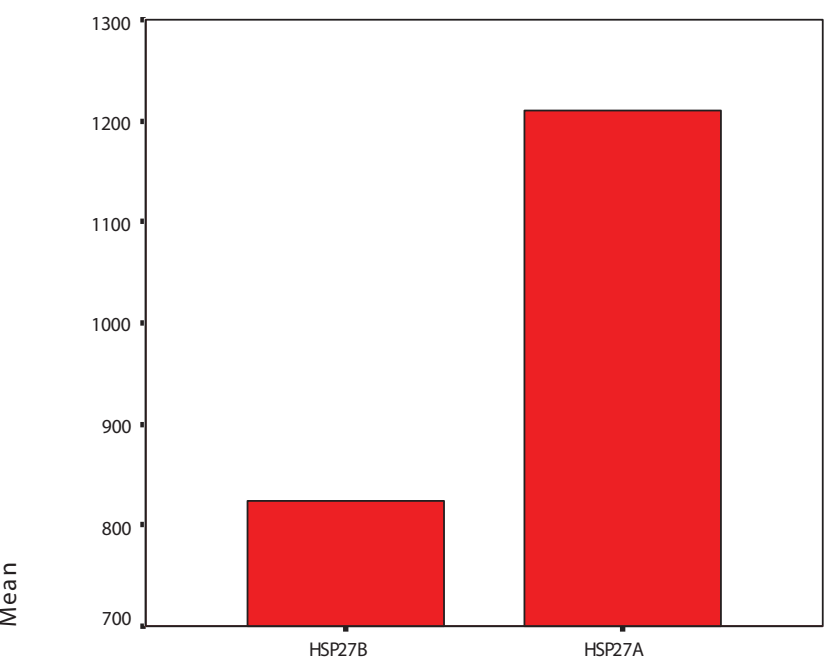

Figure 2: Heat shock protein-27 expression was significantly higher $(p<0.05)$ at the end-HD (hsp27a) than pre-HD (hsp27b).

Citation: Griveas I (2020) Heat-Shock Protein 27 kinetics in end stage renal disease patients. Arch Clin Nephrol 6(1): 024-030. 
Another parameter very controversial in literature is modality of $\mathrm{HD}$, therefore we evaluated patients receiving regular HD and patients receiving on line Hemodiafiltration (HDF) Table 4. We noticed that patients under regular HD had higher values of HSP-27 than the patients under on-line HDF, although not significant (NS). There were similar findings to the other cytokines. In the case of IL-1 $\beta$ at the end of session, IL- 8 before and at the end of session, IL-10 and TNF- $\alpha$ at the end of session values during on-line HDF were significantly lower.

In order to estimate the significance of all the above results and their possible link between new "tools" and "traditional"
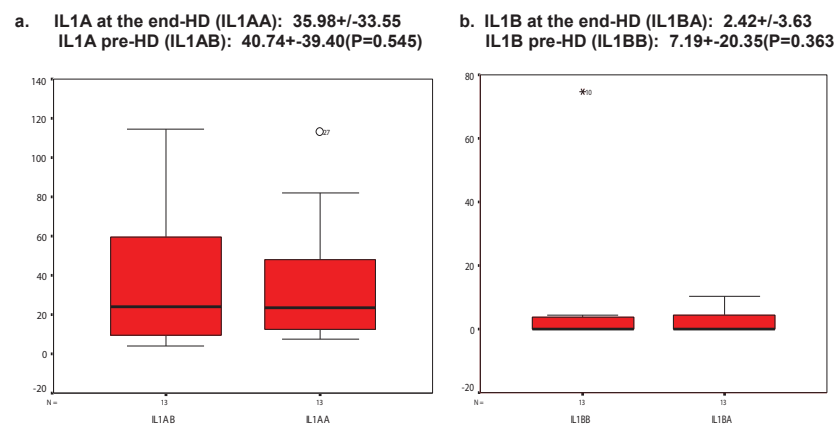

c. IL2 at the end-HD (IL2A): $5.55+/-4.59$ IL2 pre-HD (IL2B): $6.43+-3.03(P=0.344)$
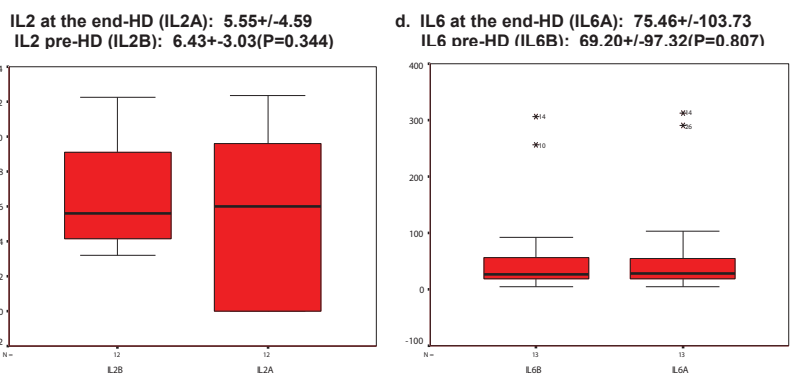

IL8 at the end-HD (IL8A): $31.70+/-23.92$
IL8 pre-HD (IL8B): $33.19+-26.33(P=0.824$

f. IL10 at the end-HD (IL10A): $32.30+/-19.11$
IL10 pre-HD (IL10B): $35.37+/-13.52(P=0.539)$ pre-HD (L8B): $33.19+-26.33(P=0.824)$

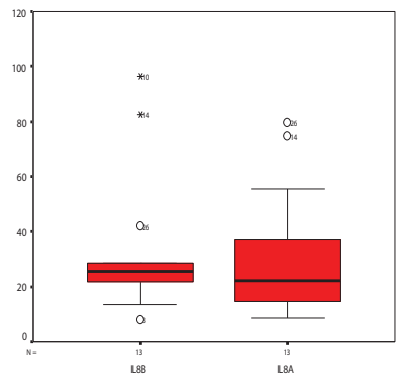

g. TNFA end-HD (TNFAA): $30.19+1-26.57$ TNFA pre-HD (TNFAB): $33.51+-19.17(\mathrm{P}=0.592)$
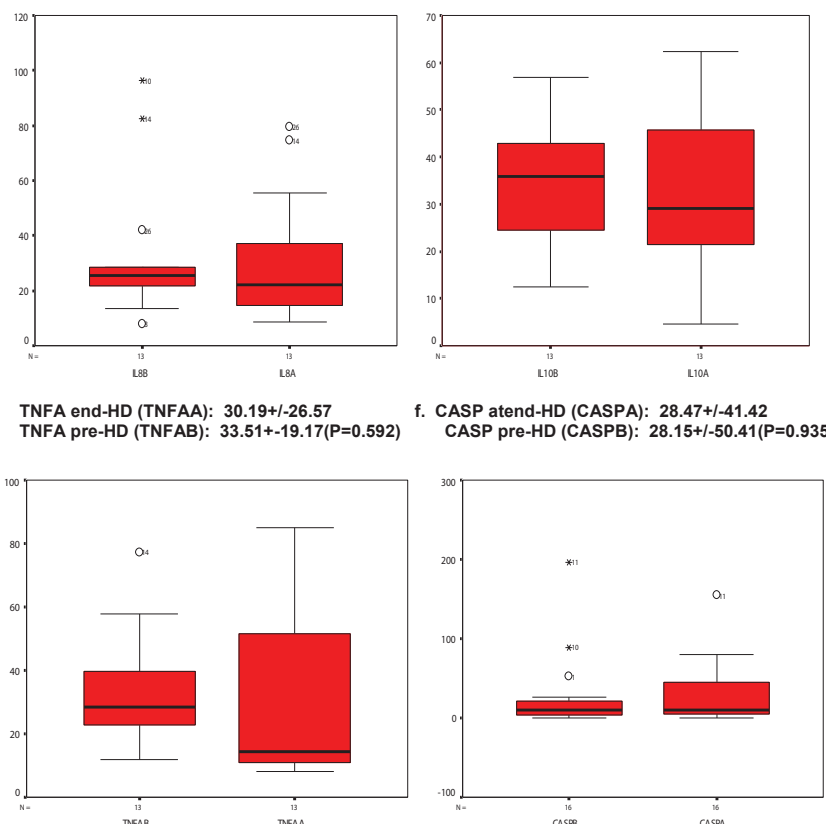

f. CASP atend-HD (CASPA): $28.47+/-41.42$ CASP preHD (CASPB): $28.15+1-50.41(\mathrm{P}=0.935)$

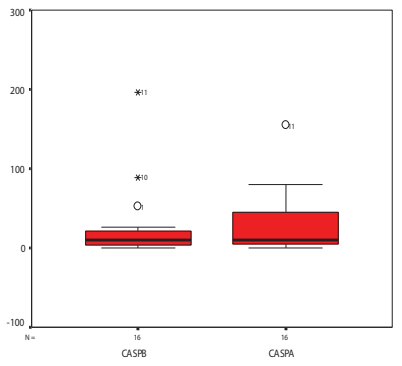

Figure 3: Cytokines and caspase kinetics during HD session.

Table 2: Comparison among patients receiving HD with low or high flux membranes.

\begin{tabular}{|c|c|c|c|}
\hline Type of membrane & Low flux & High flux & $P$ value \\
\hline HSP-27 PRE-HD & $945.36+/-735.17$ & $701.48+/-154.41$ & NS \\
\hline HSP-27 END-HD & $1395.55+/-975.29$ & $1026.30+/-652.24$ & NS \\
\hline HSP-27 DIALYSATE & $0.92+/-1.53$ & $5.72+/-7.62$ & NS \\
\hline IL-1A PRE-HD & $54.13+/-45.46$ & $25.11+/-26.48$ & NS \\
\hline IL-1A END-HD & $44.03+/-38.39$ & $26.58+/-27.12$ & NS \\
\hline IL-1A DIALYSATE & $5.79+/-0.92$ & $6.24+/-0.97$ & NS \\
\hline IL-1B PRE-HD & $12.33+27.54$ & $1.18+/ 1.83$ & NS \\
\hline IL-1B END-HD & $2.62+/-3.88$ & $2.19+/-3.67$ & NS \\
\hline IL-1B DIALYSATE & 0 & 0 & NS \\
\hline IL-2 PRE-HD & $6.91+/-3.47$ & $5.94+/-2.75$ & NS \\
\hline IL-2 END-HD & $5.54+/-5.14$ & $5.55+/-4.46$ & NS \\
\hline IL-2 DIALYSATE & 0 & 0 & NS \\
\hline IL-6 PRE-HD & $72.57+/-84.79$ & $65.27+/-118.16$ & NS \\
\hline IL-6 END-HD & $42.88+/-30.40$ & $113.47+146.62$ & NS \\
\hline IL-6 DIALYSATE & 0 & 0 & NS \\
\hline IL-8 PRE-HD & $35.26+/-27.01$ & $30.77+/-27.85$ & NS \\
\hline IL-8 END-HD & $29.95+13.94$ & $33.74+/-33.83$ & NS \\
\hline IL-8 DIALYSATE & 0 & 0 & NS \\
\hline IL-10 PRE-HD & $31.65+/-15.45$ & $39.71+/-10.48$ & NS \\
\hline IL-10 END-HD & $33.76+/-14.34$ & $30.59+/-24.96$ & NS \\
\hline IL-10 DIALYSATE & 0 & 0 & NS \\
\hline TNF-A PRE-HD & $34.41+/-17.51$ & $32.47+/-22.63$ & NS \\
\hline TNF-A END-HD & $35.08+/-30.49$ & $24.48+/-22.52$ & NS \\
\hline TNF-A DIALYSATE & 0 & 0 & NS \\
\hline CASPASE PRE-HD & $48.68+/-66.74$ & $7.62+/-5.35$ & NS \\
\hline CASPASE END-HD & $47.25+/-51.94$ & $9.68+/-13.12$ & NS \\
\hline CASPASE DIALYSATE & 0 & 0 & NS \\
\hline
\end{tabular}

parameters (e.g. Hct, PTH) firstly we re-evaluated the same group of patients after 3 months, on the basis of the same figures. During this period, as it has been shown in Table 5, we did not notice any significant differences apart from albumin and IL-1 $\beta$ at the end of session. Appling regression analysis we concluded that HSP-27 was predictive for $\mathrm{Hb}(\mathrm{r}=-0.555)$, PTH ( $r=0.873)$, albumin $(r=0.510)$ but not for CRP (Figure 2). Spitting the influence of each parameter we noticed that apart from HSP-27, caspase-3 ( $r=0.499)$ and IL-1 $\beta(r=0.609)$ were predictive for $\mathrm{Hb}$ value (Figure 3 ). Values of Hct were influenced by IL-1 $\beta(r=0.672)$ and IL-8 $(r=0.598)$ (Figure 4).

\section{Discussion}

The term "heat shock" protein is a misnomer but remains as a legacy of Ritossa's serendipitous discovery that heat shock produced chromosomal puffs of salivary gland cells in Drosophila. Heat stress $\left(\geq 5^{\circ}\right.$ normal growth temperature) upregulates the rapid synthesis of a multigene family of proteins, originally called heat shock proteins, which are the result of a response often referred to as the heat shock response [5,6]. Prior sublethal heat stress transiently increases the ability of a cell to withstand an otherwise lethal subsequent heat challenge. This phenomenon, or thermotolerance, played

Citation: Griveas I (2020) Heat-Shock Protein 27 kinetics in end stage renal disease patients. Arch Clin Nephrol 6(1): 024-030. 
a key role in launching numerous studies in both in vitro and in vivo experimental studies in which a similar association was found between the heat shock response and protection against either simulated hypoxia or ischemia.

Indeed, diverse stresses, including heavy metals, amino acids analogues, inflammation and oxidative/ischemic stress induce the expression of HSP genes. Consequently, the terms "stress proteins" or "heat shock family of stress proteins"are preferred, although many of these proteins have essential functions during unstressed conditions $[3,7]$. Stress proteins belong to multigene families that range in molecular size from 10 to $150 \mathrm{kDa}$ and are found in all major cellular compartments. The convection is to name stress proteins of various molecular sizes as follows: HSP 27, HSP 70 and HSP 90 [3].

In our study we used HSP 27, which after its discovery as an inhibitor of actin polymerization, has been demonstrated to play a major role in actin filament dynamics in diverse cell types. Physiological stimuli (oxidative stress, cytokines and growth factors) dramatically increase the phosphorylation of human HSP 27 at Ser15, Ser78, and Ser 83 residues, which is essential for acquired tolerance [8]. HSP27 phosphorylation is catalysed by the MARKs (p-38-MARKs, JNKs, or SARKs) and

Table 3: Comparison among patients receiving HD with synthetic or with membranes made of natural polymers.

\begin{tabular}{|c|c|c|c|}
\hline Material of membrane & Synthetic & Natural polymers & $P$ value \\
\hline HSP-27 PRE-HD & $656.99+/-184.28$ & $1544.63+/-184.28$ & $<0.05$ \\
\hline HSP-27 END-HD & $1070.45+/-789.46$ & $1819.63+/-818.53$ & NS \\
\hline HSP-27 DIALYSATE & $3.76+/-6.39$ & $1.43+/-2.48$ & NS \\
\hline IL-1A PRE-HD & $46.15+/-40.65$ & $10.96+/-2.42$ & $<0.05$ \\
\hline IL-1A END-HD & $40.05+/-35.09$ & $13.56+/-1.72$ & NS \\
\hline IL-1A DIALYSATE & $6.02+/-1.01$ & $5.86+/-0.15$ & NS \\
\hline IL-1B PRE-HD & $8.14+22.13$ & $1.93+/ 2.73$ & NS \\
\hline IL-1B END-HD & $2.87+/-3.80$ & 0 & $<0.05$ \\
\hline IL-1B DIALYSATE & 0 & 0 & NS \\
\hline IL-2 PRE-HD & $6.54+/-3.34$ & $5.87+/-0.18$ & NS \\
\hline IL-2 END-HD & $5.61+/-5.07$ & $5.22+/-0.36$ & NS \\
\hline IL-2 DIALYSATE & 0 & 0 & NS \\
\hline IL-6 PRE-HD & $78.51+/-103.74$ & $18.72+/-0.19$ & NS \\
\hline IL-6 END-HD & $85.98+/-110.09$ & $17.59+2.36$ & NS \\
\hline IL-2 DIALYSATE & 0 & 0 & NS \\
\hline IL-8 PRE-HD & $34.33+/-28.68$ & $26.90+/-2.18$ & NS \\
\hline IL-8 END-HD & $30.10+24.97$ & $40.46+/-26.20$ & NS \\
\hline IL-8 DIALYSATE & 0 & 0 & NS \\
\hline IL-10 PRE-HD & $32.55+/-12.58$ & $50.88+/-6.39$ & NS \\
\hline IL-10 END-HD & $30.18+/-20.14$ & $43.92+/-2.99$ & NS \\
\hline IL-10 DIALYSATE & 0 & 0 & NS \\
\hline TNF-A PRE-HD & $37.20+/-18.53$ & $13.23+/-2.01$ & NS \\
\hline TNF-A END-HD & $33.18+/-27.99$ & $13.72+/-0.71$ & NS \\
\hline TNF-A DIALYSATE & 0 & 0 & \\
\hline CASPASE PRE-HD & $18+/-25.45$ & $72.16+/-107.70$ & NS \\
\hline CASPASE END-HD & $21.46+/-26.77$ & $58.83+/-82.86$ & \\
\hline CASPASE DIALYSATE & 0 & 0 & \\
\hline
\end{tabular}

Table 4: Comparison among patients receiving either regular HD or on-line Hemodiafiltration

\begin{tabular}{|c|c|c|c|}
\hline Type of dialysis modality & Regular HD & On-line HDF & P value \\
\hline HSP-27 PRE-HD & $882.65+/-662.23$ & $724.71+/-171.86$ & NS \\
\hline HSP-27 END-HD & $1243.25+/-919.58$ & $1157.05+/-713.94$ & NS \\
\hline HSP-27 DIALYSATE & $2.25+/-4.61$ & $5.11+/-7.65$ & NS \\
\hline IL-1A PRE-HD & $43.63+/-44.56$ & $34.22+/-28.85$ & NS \\
\hline IL-1A END-HD & $36.92+/-36.17$ & $33.86+/-31.67$ & NS \\
\hline IL-1A DIALYSATE & $5.87+/-0.88$ & $6.29+/-1.10$ & NS \\
\hline IL-1B PRE-HD & $10.01+24.31$ & $0.83+/ 1.66$ & NS \\
\hline IL-1B END-HD & $3.50+/-0.94$ & 0 & $<0.05$ \\
\hline IL-1B DIALYSATE & 0 & 0 & \\
\hline IL-2 PRE-HD & $6.90+/-3.02$ & $5.48+/-3.25$ & NS \\
\hline IL-2 END-HD & $6.55+/-4.73$ & $3.54+/-4.11$ & NS \\
\hline IL-2 DIALYSATE & 0 & 0 & \\
\hline IL-6 PRE-HD & $92.85+/-110.05$ & $15.99+/-11.50$ & NS \\
\hline IL-6 END-HD & $100.18+/-107.22$ & $19.39+18.56$ & NS \\
\hline IL-6 DIALYSATE & 0 & 0 & \\
\hline IL-8 PRE-HD & $41.24+/-28.12$ & $15.07+/-5.80$ & 0.99 \\
\hline IL-8 END-HD & $40.43+23.90$ & $12.05+/-4.81$ & $<0.05$ \\
\hline IL-8 DIALYSATE & 0 & 0 & \\
\hline IL-10 PRE-HD & $35.71+/-16.01$ & $34.59+/-6.79$ & NS \\
\hline IL-10 END-HD & $39.71+/-17.16$ & $15.62+/-11.84$ & $<0.05$ \\
\hline IL-10 DIALYSATE & 0 & 0 & \\
\hline TNF-A PRE-HD & $36.89+/-22.47$ & $25.92+/-3.57$ & NS \\
\hline TNF-A END-HD & $39.14+/-27.61$ & $10.06+/-3.37$ & $<0.05$ \\
\hline TNF-A DIALYSATE & 0 & 0 & \\
\hline CASPASE PRE-HD & $41+/-61.06$ & $6.75+/-5.67$ & NS \\
\hline CASPASE END-HD & $39.6+/-48.58$ & $9.91+/-15.43$ & NS \\
\hline CASPASE DIALYSATE & 0 & 0 & \\
\hline
\end{tabular}

ERKs. In the perfused adult heart, both p38-MARK and JNK/ SARK are activated after ischemia/reperfusion. In response to ROS treatment, activation of p-38-MARK increases MAPKAP kinase 2 activity, which phosphorylates HSP 27 [9].

In human endothelial cells, inhibition of vascular endothelial growth factor-induced p38-MARK activation abolishes HSP27 phosphorylation, actin polymerization and cell migration, suggesting a possible link between HSP27 and angiogenesis Together, available evidence places the p-38-MARK as an upstream activator of stress inducible HSP27phosphorylation, and this pathway underlies the effect of p-38-MARK on the reorganization of filamentous actin, accumulation of stress fibers and the recruitment of vinculin at focal adhesion sites It will be important next to determine whether HSP27 exerts vasoprotective actions in response to hemodynamic forces or vessel wall injury. However, direct analysis will likely require an HSP27 gene knockout model [10].

This study appears to be the first to use Luminex technology in order to find a potential link between HSP, cytokines and HD parameters. At first we noticed a significant higher expression of HSP-27 at the end of HD session, possibly due 
to attenuate apoptosis [11]. However functional studies need to be performed to confirm the proposed hypothesis. Some observations have been done by Raj, et al. although the number of patients were smaller and determination of HSP using ELISA [12]. The increase of HSP has been also noticed in muscle of HD patients. A potential speculative explanation for this increase is that muscle of patients is exposed to chronic oxidative stress but has successfully adapted to this stress with little evidence of ongoing reactive oxygen species (ROS) generation [13].

Evaluating all the other parameters, we did not notice any significant differences during HD session. Despite of that finding the general idea is that all cytokines tend to get lower at the end of session with exeption of IL- 6 which gets higher. Plasma levels of IL- 6 increased significantly during HD session in other studies [12]. Researchers demonstrated that plasma levels of s IL-6R and soluble gp 130 also increased during HD

Table 5: Comparison among patients after 3 months period.

\begin{tabular}{|c|c|c|c|}
\hline Time Beginning & At the End & $P$ value & \\
\hline $\mathrm{Hb}(\mathrm{g} / \mathrm{dl})$ & $12.58+/-1.28$ & $12.67+/-0.71$ & NS \\
\hline Hct (\%) & $37.42+/-4.16$ & $38.04+/-1.90$ & NS \\
\hline PTH (pg/ml) & $318+/-340$ & $213+/-45$ & NS \\
\hline Ferritine & $350+/-184$ & $442+/-212$ & NS \\
\hline Albumine & $4.44+/-0.34$ & $4.07+/-0.21$ & $<0.05$ \\
\hline CRP & $0.85+/-0.54$ & $1.70+/-2.56$ & NS \\
\hline HSP-27 PRE-HD & $912.85+/-666.98$ & $708.44+/-278.31$ & NS \\
\hline HSP-27 END-HD & $1110.57+/-722.95$ & $1339.94+/-983.08$ & NS \\
\hline HSP-27 DIALYSATE & $1.61+/-1.98$ & $5.52+/-8.40$ & NS \\
\hline IL-1A PRE-HD & $46.35+/-45.06$ & $34.19+/-34.53$ & NS \\
\hline IL-1A END-HD & $34.14+/-30.83$ & $38.12+/-39.37$ & NS \\
\hline IL-1A DIALYSATE & $6.15+/-0.82$ & $5.82+/-1.09$ & NS \\
\hline IL-1B PRE-HD & $12.26+27.57$ & $1.27+/ 1.99$ & NS \\
\hline IL-1B END-HD & $2.70+/-3.91$ & $2.10+/-3.61$ & $<0.05$ \\
\hline IL-1B DIALYSATE & 0 & 0 & \\
\hline IL-2 PRE-HD & $6.14+/-2.47$ & $6.72+/-3.73$ & NS \\
\hline IL-2 END-HD & $5.89+/-5.10$ & $5.21+/-4.48$ & NS \\
\hline IL-2 DIALYSATE & 0 & 0 & \\
\hline IL-6 PRE-HD & $108.10+/-122.45$ & $23.81+/-12.08$ & NS \\
\hline IL-6 END-HD & $84.01+/-105.54$ & $65.48 .39+110.62$ & NS \\
\hline IL-6 DIALYSATE & 0 & 0 & \\
\hline IL-8 PRE-HD & $40.40+/-34.22$ & $24.78+/-10.07$ & NS \\
\hline IL-8 END-HD & $36.58+15.94$ & $33.95+/-11.36$ & $<0.05$ \\
\hline IL-8 DIALYSATE & 0 & 0 & \\
\hline IL-10 PRE-HD & $35.71+/-16.01$ & $34.59+/-6.79$ & NS \\
\hline IL-10 END-HD & $36.11+/-18.76$ & $27.85+/-20.24$ & NS \\
\hline IL-10 DIALYSATE & 0 & 0 & \\
\hline TNF-A PRE-HD & $38.49+/-21.05$ & $27.71+/-16.60$ & NS \\
\hline TNF-A END-HD & $28.38+/-29.81$ & $32.31+/-24.88$ & NS \\
\hline TNF-A DIALYSATE & 0 & 0 & \\
\hline CASPASE PRE-HD & $42.83+/-64.45$ & $9.28+/-8.71$ & NS \\
\hline CASPASE END-HD & $36.44+/-52.86$ & $18.21+/-18.58$ & NS \\
\hline CASPASE DIALYSATE & 0 & 0 & \\
\hline
\end{tabular}

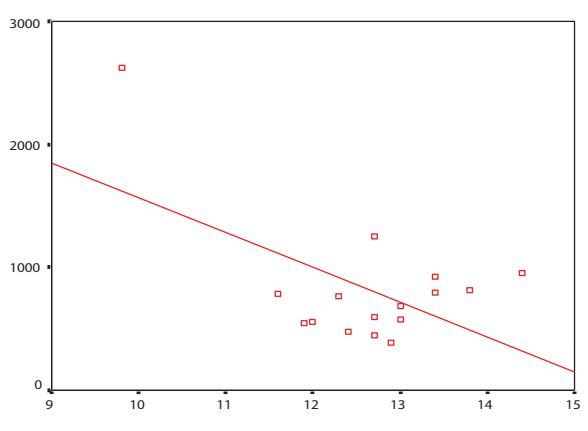

$\mathrm{HB}$

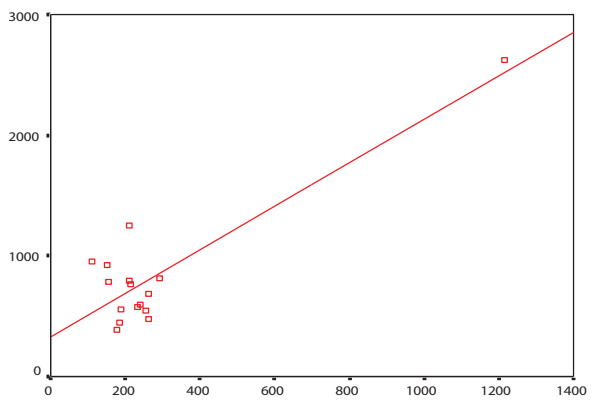

PTH
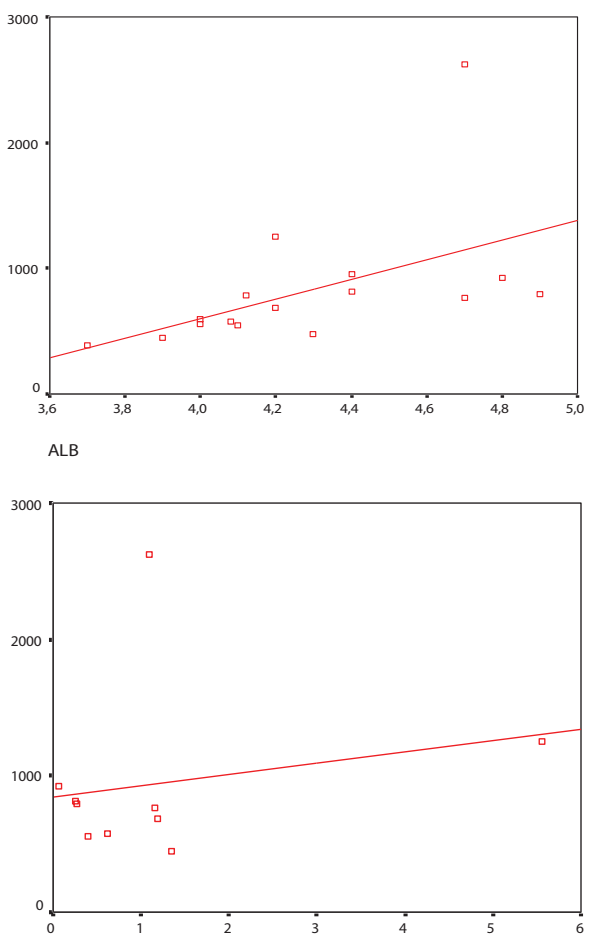

CRP

Figure 4: Regressionanalysisbetween HSP-27, Hb, PTH, albumine.

session. IL-6 mediated its effects on target cells via a complex receptor system composed on ligand binding subunit and signal transducing glycoprotein [14].

IL- 5 was not detectable at all in blood samples of our patients. In dialysate HSP -27 was slightly detectable (3.32+/5.86) and the same with IL-1A (6+/-0.93). All the other 

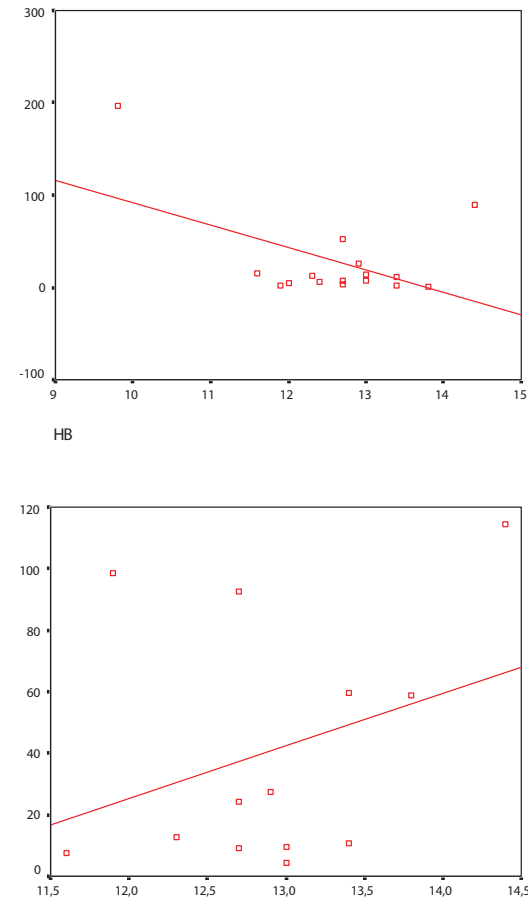

Figure 5: Regressionanalysisbetween caspase-3, IL-1 $\beta$ and $\mathrm{Hb}$.

cytokines and caspase could not be scouted in dialysate. With the current amount of data there is not strong explanation of the above remarks. It is certain therefore that the above results can open the discussion concerning critical points such as, clearances of dialyzers, structure of HSP and cytokines and its possible relation to HD modalities, etc.

Comparing low-high flux dialyzers the first impression is that HSP is not an adequate tool. Reading between the lines we may emphasize the point of greater values of HSP in patients with low-flux dialyzers. At the same time, paradox conclusions came up when comparing material of dialyzer. HSP-27 values were significantly higher in patients undergoing HD with natural polymers. On the contrary, values of cytokines were generally higher in patients receiving $\mathrm{HD}$ with synthetic membranes with the exeption of IL-10. In IL-1A pre-HD and in IL-1 $\beta, T N F-\alpha$ at the end of HD these differences were significant.

There are not data regarding HSP and dialyzers in HD. We know that dialysis may result in introduction of various chemicals into the circulation from dialysis tubing which may induce sublethal injury to the tubular cells and induce their proliferation [15]. Recent studies have documented that the kidney in ESRD is not a resting organ. It shows high proliferative activity of the tubular epithelial cells compared with normal kidney [16]. It has been suggested that HD causes more stress or injury to the tubular stress or injury to the tubular cells superimposed on an already compromised situation of ESRD, leading to a higher rate of tubular cell proliferation associated with more hyperplastic super tubule formation which may be the forerunner of cyst formation as well as neoplastic formation [17].
Having under consideration the above data, a new area of research is opened. HSP has been proposed as biocompatibility test in peritoneal dialysis [18]. The role of stress proteins in cardioprotection has been acknowledged as one of the most important future directions of research in ischemic heart disease [19]. Opportunities to address the physiological roles of cytoprotective chaperones in cardiac diseases need to be expanded to include their likely roles during chronic conditions (atherosclerosis, hypertension, diabetes, genetic disorders and vascular heart disease) that converge though common pathways, resulting in heart failure and sudden death. ESRD patients under HD with different dialyzers must be study area of research teams, which could forge new directions and accelerate progress in the promising area of biocompatibility. HSP proteins appear to get involved at the same time to function of native kidneys, dialyzers and endothelial dysfunction and may succeed in exploiting endogenous pathways to enhance physiological health and to reduce physiological attrition associated with cardiovascular diseases.

The success of dialysis as a long term treatment is weighted by the increasingly reported incidence of dialysis-specific morbidity. Dialysis-Related Pathology (DRP), including amyloidosis, atherosclerosis, hypertrophic cardiomyopathy, aortic stenosis and nutrition is prelevant after 10 years of renal replacement therapy (RRT). Taking a simplistic approach, one might speculate that DRP, has multiple causes with possible overlap: the low overall efficiency of RRT when compared with native kidneys, the lack of selectivity in solute removal capacity, the relative shortfall in correcting metabolic abdormalities, and the haemobiologic incompatibility of the dialysis system resulting in the periodic activation of proinflammatory proteins and cell systems [20]. To our present knowledge, on-line HDF provides the most haemocompatible system for RRT. Our remarks showed that patients under on-line HDF had lower values (not significant) of HSP-27 and caspase comparing with those under regular HD, confirming the above conclusion. HDF limits the patient-dialysis system interaction to the contact of blood with the arterial and venous tubing of the extracorporeal circuit. It provides the first approach to reach the full haemocompatibilty test and HSP family may be a new accurate test.

It has been reported that the plasma production of cytokines did not result in significant differences when the monocytes were incubated with either on-line prepared reinfusate or commercially convective procedures [21]. In our study in most cases the cytokines levels were significantly lower in patients under on-line HDF. This clue has its importance since the first proposal of the "cytokine hypothesis" [22], where many uraemic features have eventually been attributed to chronic cytokine activation: cardiovascular instability, malnutrition, induction of hepatic acute-phase proteins, etc. Several studies have shown that the HD procedure is associated with the activation of an inflammatory cascade as evidenced by increases mainly in IL-6. The above activation has been attributed to exposure of blood to dialysis membranes and/or back-leakage of lipopolysaccharide through the dialysis membranes due to the use of less-than-sterile dialysate. In support of the latter, it has been shown that use of ultrapure, endotoxin-free 
dialysate (which is used in on-line HDF) resulted in reduced blood concentrations of proinflammatory cytokines [23].

Owing to its high prevalence in patients with ESRD, chronic inflammation is proposed as a potential catabolic factor that worsens the nutritional status of these patients. Inflammation, more recently termed systemic inflammatory response, is a complex combination of physiological, immunological and metabolic effects occurring in response to a variety of stimulators resulting from tissue injury or disease processes. Certain cytokines, such as IL-1,IL-6, and tumor necrosis factor TNF $-\alpha$ are the primary mediators of these effects and the predominant metabolic effects of these cytokines are catabolic (influencing $\mathrm{Hb}$, albumin etc). Therefore, it is important for the host to limit their biological activities by eliciting a strong anti-inflammatory response [24].

In order to evaluate the significance and the possible link between new "tools" and "traditional" parameters (e.g. Hct, PTH) at first we re-evaluated the same patients after 3 months on the basis of the same figures. Appling regression analysis we concluded that HSP-27 was predictive for $\mathrm{Hb}, \mathrm{Hct}, \mathrm{PTH}$, albumin but not for CRP (Figure 5). Spitting the influence of each parameter we noticed that apart from HSP-27, caspase-3 and IL-1 $\beta$ were predictive for $\mathrm{Hb}$ value. Values of Hct were influenced by IL-1 $\beta$ and IL-8. It seems from the above remarks that HSP-27 may be a new link, apart from cytokines, between "chronic inflammation" and "traditional" parameters such as $\mathrm{Hb}, \mathrm{PTH}$, albumin.

The present study is unique in showing a correlation between HSP-27 and the manifestation of atherosclerosis in ESRD patients. It seems that HD modalities and biocompatibility in general, play a vital role. In conclusion, our data provide further evidence for the hypothesis of an autoimmune induction of early inflammatory arteriosclerotic changes. Further studies are necessary to determine whether HSP-27 has diagnostic and prognostic value in patients on chronic hemodialysis.

\section{References}

1. Xu Q, Dietrich H, Steiner HJ, Gown AM, Schoel B, et al. (1992) Induction of arteriosclerosis in normocholesterolaemic rabbits by immunization with heat shock protein 65. Arterioscler Tromb 12: 789-799. Link: https://bit.ly/3kmxTc2

2. Kleindienst R, Schett G, Amberger A, Seitz CS, Michaelis D, et al. (1995) Atherosclerosis as an autoimmune condition. Isr J Med Sci 31: 596-599. Link:

3. Benjamin IJ, McMillan DR (1998) Stress (Heat Shock) Proteins, Molecular chaperones in cardiovascular biology and disease. Circ Res 83: 117-132. Link: https://bit.ly/2H6blOk

4. Raj DSC, Dominic EA, Pai A, Osman F, Morgan M, et al. (2005) Skeletal muscle cytokines and oxidative stress in end-stage renal disease. Kidney Int 68: 2338 2344. Link: https://bit.ly/3hBHw4P

5. Lindquist S, Craig EA (1988) The heat shock proteins.Annu Rev Genet 22: 631 677. Link: https://bit.ly/32wPaJg

6. Ritossa F (1996) Discovery of the heat shock response. Cell Stress Chaperones 1: 97-98. Link: https://bit.ly/2RxErYY
7. Hartl F (1996) Molecular chaperones in cellular protein folding. Nature 381 571-579. Link: https://go.nature.com/2ZGmrzY

8. Huot J, Houle F, Spitz DR, Landry J (1996) HSP 27 phosphorylation-mediated resistance against actin fragmentation and cell death induced by oxidative stress. Cancer Res 56: 273-279. Link: https://bit.ly/2RIUDqt

9. Bogoyevitch MA, Gillespie-Brown J, Ketterman AJ, Fuller SJ, Ben-Levy R, et al (1996) Stimulation of the stress-activated mitogen-activated protein kinase subfamilies in perfused heart: p38/RK mitogen-activated protein kinases and c-Jun N-terminal kinases are activated by ischemia/reperfusion. Circ Res 79 162-173. Link: https://bit.ly/2FCYFOL

10. Rousseau S, Houle F, Landry J, Huot J (1997) p38 MAP kinase activation by vascular endothelial growth factor mediates actin reorganization and cell migration in human endothelial cells. Oncogene 15: 2169-2177. Link: https://bit.ly/3knx0jq

11. Shang J, Eberle J, Geilen CC, Hosiini AM, Fecker LF, et al. (2002) The role of nuclear factor-kappa B and melanogenesis in tumor necrosis factor-alphainduced apoptosis of normal human melanocytes. Skin Pharmacol Appl Skin Physiol 15: 321-329. Link: https://bit.ly/3c4sumW

12. Raj DC, Boilvin MA, Dominic EA, Boyd A, Roy PK, et al. (2007) Haemodialysis induces mitochondrial dysfunction and apoptosis. Eur J Clin Invest 37: 971977. Link: https://bit.ly/3mqu3QV

13. Crowe A, McArdle A, McArdle F, Pattwell DM, Bell GM, et al. (2007) Markers of oxidative stress in the skeletal muscle of patients on haemodialysis.Nephrol Dial Transplant 22: 1177-1183. Link: https://bit.ly/3hAWYOM

14. Memoli B, Grandaliano G, Soccio M, Postiglione L, Guida B, et al. (2005) In vivo modulation of soluble antagonistic IL-6 receptor synthesis and release in ESRD. J Am Soc Nephrol 16: 1099-1107. Link: https://bit.ly/3mtyGtg

15. Crocker JFS, Safe SH (1984) An animal model of hemodialysis-induced polycystic kidney disease. Kidney Int 25: 183-187.

16. Nasasdy T, Laszik Z, Blick RE, Johnson DL, Sillva FG (1994) Tubular atrophy in the end stage kidney: a lectin and immune-histochemical study. Hum Pathol 25: 22-28. Link: https://bit.ly/2RwIPaA

17. Dinda AK, Mathur M, Guleria S, Saxena S, Tiwari SC, et al. (1998) Heat shock protein expression and proliferation of tubular cells in end stage renal disease with and without haemodialysis. Nephrol Dial Transplant 13: 99-105. Link: https://bit.ly/33BSnqg

18. Bidmon B, Endemann M, Arbeiter K, Ruffingshofer D, Regele H, et al. (2007) Overexpression of HSP-72 confers cytoprotection in experimental peritoneal dialysis. Kidney Int 66: 2300-2307. Link: https://bit.ly/3iCSdoV

19. Black SC, Lucchhesi BR (1993) Heat shock proteins and the ischemic heart: an endogenous protective mechanism. Circulation 87: 1048-1051. Link: https://bit.ly/32ywysi

20. Canaud B, BoscJY, Leray H, Stec F, Argiles A, et al. (1998) On-line haemodiafiltration: state of the art. Nephrol Dial Transplant 13: 3-11. Link: https://bit.ly/33Ebb8C

21. Pizzarelli F, Maggiore Q (1998) Clinical perspectives of online haemodiafiltration. Nephrol Dial Transplant 13: 34-37. Link https://bit.ly/2ZF3098

22. Henderson LW, Koch KM, Dinarello CA, Shaldon S (1983) Hemodialysis hypotension: the interleukin-1 hypothesis. Blood Purif 1: 3-8. Link: https://bit.ly/2Fs4n5U

23. Caglar K, Peng Y, Pupim LB, Flakoll PJ, Levenhagen D, et al. (2002) Inflammatory signals associated with hemodialysis. Kidney Int 62: 1408-1416. Link: https://bit.ly/2H6vgwz

24. Ikizler TA (2008) Nutrition, Inflammation and chronic kidney disease. Curr Opin Nephrol Hypertens 17: 162-167. Link: https://bit.ly/32zqfoH

Copyright: (c) 2020 Griveas I. This is an open-access article distributed under the terms of the Creative Commons Attribution License, which permits unrestricted use, distribution, and reproduction in any medium, provided the original author and source are credited.

Citation: Griveas I (2020) Heat-Shock Protein 27 kinetics in end stage renal disease patients. Arch Clin Nephrol 6(1): 024-030.

DOI: https://dx.doi.org/10.17352/acn.000043 